\title{
Nd:YAG laser irradiation associated with fluoridated gels containing photo absorbers in the prevention of enamel erosion
}

\author{
LGS Pereira $^{1} \cdot$ SH Joao-Souza $^{1}$ - SJC Bezerra ${ }^{1}$ - AB Borges ${ }^{2} \cdot$ ACC Aranha $^{1}$. \\ T Scaramucci ${ }^{1}$
}

Received: 1 September 2016 / Accepted: 28 April 2017 /Published online: 12 May 2017

(C) Springer-Verlag London 2017

\begin{abstract}
This study evaluated the combined effect of Nd:YAG laser irradiation and fluoridated gels containing photo absorbers against enamel erosion. Enamel specimens from bovine teeth were polished, eroded ( $10 \mathrm{~min}$, with $1 \%$ citric acid, $\mathrm{pH}=2.6$ ), and randomly allocated into the experimental groups $(\mathrm{n}=8)$, according to the different surface treatments: fluoridated gels (F: 9047 ppm F and F + Sn: 9047 ppm F and 3000 ppm Sn), with or without photo absorbers (E: erythrosine and MB: methylene blue), and associated or not with Nd:YAG laser irradiation (in contact; $0.5 \mathrm{~W} ; 50 \mathrm{~mJ} ; \sim 41.66 \mathrm{~J} / \mathrm{cm}^{2} ; 10 \mathrm{~Hz} ; 40 \mathrm{~s}$; pulse duration of $120 \mu \mathrm{s})$. A placebo gel (PLA) associated or not with laser was used as control. All gels had $\mathrm{pH}=4.5$ and were applied for $2 \mathrm{~min}$. Laser irradiation was performed during gel application. The specimens were then submitted to a 5-day erosionremineralization cycling model using $0.3 \%$ citric acid $(\mathrm{pH}=2.6), 4 \times /$ day. Enamel surface loss (SL) was analyzed by optical profilometry in the end of the cycling (in $\mu \mathrm{m}$ ). Data were analyzed by ANOVA and Tukey tests $(\alpha=0.05)$. Means (SD) of SL for the groups were the following (different superscript letters imply significant difference among groups): PLA $(21.02 \pm 1.28)^{\mathrm{a}}$, PLA + laser $(19.20 \pm 0.96)^{\mathrm{ab}}$, laser $(17.47 \pm 1.50)^{\mathrm{b}}, \mathrm{F}+\mathrm{Sn}+\mathrm{E}+$ laser $(13.69 \pm 0.62)^{\mathrm{c}}, \mathrm{F}+\mathrm{E}+$ laser
\end{abstract}

The original version of this article was revised: The first author name was incorrectly captured. The given name and family name were interchanged. The correct name is shown in the author group section.

T Scaramucci

tais.sca@usp.br

1 Department of Restorative Dentistry, School of Dentistry, University of São Paulo, Av. Prof. Lineu Prestes 2227, São

Paulo, SP 05508-000, Brazil

2 Department of Restorative Dentistry, Institute of Science and Technology, São Paulo State University-UNESP, Av. Eng. Francisco Jose Longo 777, Jardim São Dimas, Sao Jose dos

Campos, SP 12245-000, Brazil
$(13.52 \pm 1.16)^{\mathrm{c}}, \mathrm{F}(13.10 \pm 1.08)^{\mathrm{c}}, \mathrm{F}+$ laser $(11.94 \pm 1.44)^{\mathrm{cd}}, \mathrm{F}+$ $\mathrm{Sn}+\mathrm{MB}+$ laser $(11.90 \pm 4.02)^{\mathrm{cd}}, \mathrm{F}+\mathrm{MB}+$ laser $(11.42 \pm 1.42)^{\mathrm{cd}}, \mathrm{F}+\mathrm{Sn}(11.12 \pm 1.20)^{\mathrm{cd}}$, and F + Sn + laser $(10.35 \pm 0.89)^{\mathrm{d}}$. In conclusion, all fluoridated gels and the $\mathrm{Nd}$ :YAG laser irradiation reduced erosion development, but the combination of treatments did not promote further protection. The addition of photo absorbers to the fluoridated gels did not influence the anti-erosive effect of the combination of laser plus fluoridated gels.

Keywords Tooth erosion $\cdot$ Sodium fluoride $\cdot$ Stannous chloride $\cdot$ Nd:YAG laser $\cdot$ Optical profilometry

\section{Introduction}

Erosive tooth wear (ETW), which is the loss of dental hard tissues resulting from the interaction of chemical and physical phenomena on the tooth surface without bacteria involvement, can exert an impact in the long-term health of the dentition, influencing the well-being of those affected [1]. The frequent exposure of the teeth to dietary and stomach acids can cause its superficial dissolution, a process known as dental erosion [2]. Continuous acid exposure acting together with the mechanical impacts, such as toothbrushing or tooth-to-tooth contact, can result in the wear away of outer layers of enamel [3]. An early clinical sign of this process is the loss of luster, which is followed by a flattening of convex structures. Restorations appear to be above the tooth level and the tooth acquires a more yellowish appearance. In more advanced stages, tooth morphology becomes seriously compromised, often affecting the vertical dimension of the dentition. Moreover, dentin gets exposed, which could lead to a painful condition called dentin hypersensitivity $[4,5]$.

Considering that ETW has become a common finding in populations worldwide, the search for effective preventive measures for this condition is necessary $[1,6]$. Topical 
application of fluoridated products is one of the recommended approaches [7, 8]. Up until now, fluoride was tested as different compounds; however, studies have shown that metal fluoride compounds have a better performance $[9,10]$. It was also observed that products with higher fluoride concentrations have induced improved protection [11, 12], in addition to make the eroded substrate more resistant to toothbrushing abrasion and attrition [13, 14]. Examples of products with high fluoride concentrations are the gels and varnishes used in in-office treatments. The advantage of products for professional application is that they do not depend on the patient's compliance [15]; nevertheless, it is unknown whether the low frequency of application of these products would sustain longterm protection under highly erosive environments [8].

Irradiation of the dental hard tissues with lasers, such as the Nd:YAG, has also been used as an in-office approach to control ETW [15-17]. This laser acts by increasing the temperature of the dental structure, causing its melting and subsequent re-solidification. This is assumed to promote several chemical and physical changes, some of which are responsible to decrease enamel demineralization $[18,19]$. When associated with fluoride $[16,17,20]$, it was postulated that there is an increase in fluoride deposition over the dental surfaces, due to the formation of microspaces that would act as additional retention sites for fluoride [20,21]. In a previous study, the antierosive properties of the association between Nd:YAG laser and different fluoridated gels were investigated [15]. However, in this study, the laser alone was not able to significantly decrease enamel loss when compared to the control group, although there are several reports in the literature showing that Nd:YAG laser is effective in reducing enamel demineralization caused by cariogenic challenges [22,23]. The laser also failed to improve the anti-erosive effect of the fluoridated gels. Based on these results, we hypothesized that, since the $\mathrm{Nd}$ :YAG laser photons are better absorbed by some pigments
[24], if the fluoridated gels had a photo absorber, the heat promoted by the laser absorption would be more concentrated at the dental surface [25]. This would increase, therefore, the possible synergistic effect between fluoride and laser against erosion, as the erosive process, on contrary of caries, is mostly a surface phenomenon.

Thus, the hypothesis of the present study was that the addition of photo absorbers to fluoridated gels during Nd:YAG laser irradiation would concentrate the action of the laser at the enamel surface, increasing fluoride retention, thereby reducing enamel loss in face of erosive challenges.

\section{Objectives}

The objective of this study was to evaluate the effect of the association between fluoridated gels with different photo absorbers and Nd:YAG laser irradiation on enamel erosion development.

\section{Materials and methods}

\section{Experimental design}

This study followed a complete randomized experimental design with one experimental factor, surface treatment, in 11 levels (Table 1): PLA: placebo gel (without active ingredients); F (sodium fluoride gel, 9047 ppm F); F + Sn (sodium fluoride plus stannous chloride gel, $9047 \mathrm{ppm} F$ and 3000 ppm Sn); laser (Nd:YAG laser irradiation); PLA + laser: placebo gel and laser irradiation; $\mathrm{F}+$ laser (sodium fluoride gel and laser irradiation); $\mathrm{F}+\mathrm{Sn}+$ laser (sodium fluoride plus stannous chloride gel and laser irradiation); $\mathrm{F}+\mathrm{E}+$ laser (sodium fluoride gel with $5 \%$ erythrosine and laser

Table 1 Description of the groups

\begin{tabular}{|c|c|c|}
\hline Group & Description & Components \\
\hline PLA & Placebo gel & No active ingredients \\
\hline $\mathrm{F}$ & Sodium fluoride gel & 9047 ppm F \\
\hline $\mathrm{F}+\mathrm{Sn}$ & Sodium fluoride plus stannous chloride gel & 9047 ppm F; 3000 ppm Sn \\
\hline Laser & Nd:YAG laser irradiation & $400 \mu \mathrm{m}$ quartz fiber \\
\hline PLA + laser & Placebo gel and laser irradiation & No active ingredients \\
\hline $\mathrm{F}+$ laser & Sodium fluoride gel and laser irradiation & 9047 ppm F \\
\hline $\mathrm{F}+\mathrm{Sn}+$ laser & Sodium fluoride plus stannous chloride gel and laser irradiation & 9047 ppm F; 3000 ppm Sn \\
\hline $\mathrm{F}+\mathrm{E}+$ laser & Sodium fluoride gel with erythrosine and laser irradiation & 9047 ppm F; 5\% erythrosine (E) \\
\hline $\mathrm{F}+\mathrm{MB}+$ laser & Sodium fluoride gel with methylene blue and laser irradiation & 9047 ppm F; 5\% methylene blue (MB) \\
\hline $\mathrm{F}+\mathrm{Sn}+\mathrm{E}+$ laser & $\begin{array}{l}\text { Sodium fluoride plus stannous chloride gel with erythrosine and laser } \\
\text { irradiation }\end{array}$ & 9047 ppm F; 3000 ppm Sn; 5\% erythrosine (E) \\
\hline $\begin{array}{l}\mathrm{F}+\mathrm{Sn}+\mathrm{MB}+ \\
\quad \text { laser }\end{array}$ & $\begin{array}{l}\text { Sodium fluoride plus stannous chloride gel with methylene blue and laser } \\
\text { irradiation }\end{array}$ & $\begin{array}{l}9047 \text { ppm F; } 3000 \text { ppm Sn; 5\% methylene blue } \\
\text { (MB) }\end{array}$ \\
\hline
\end{tabular}


irradiation) $\mathrm{F}+\mathrm{MB}+$ laser (sodium fluoride gel with $5 \%$ methylene blue and laser irradiation); F + Sn + E + laser (sodium fluoride plus stannous chloride gel with erythrosine and laser irradiation); and $\mathrm{F}+\mathrm{Sn}+\mathrm{MB}+$ laser (sodium fluoride plus stannous chloride gel with methylene blue and laser irradiation). The anti-erosive effect of the treatments was tested in an erosion-remineralization cycling model during 5 days, using enamel specimens $(n=8)$ obtained from bovine incisors, which were previously eroded. The response variable was enamel surface loss (SL, in $\mu \mathrm{m})$, measured at the end of cycling with an optical profilometer.

\section{Specimen preparation}

Bovine incisors from young and male cattle, with similar diet, were obtained from a slaughterhouse, stored in $0.1 \%$ thymol solution under refrigeration at $4{ }^{\circ} \mathrm{C}$, until the beginning of the experiment. After cleaning with periodontal curettes, they were submitted to prophylaxis with Robinson's brush coupled in a low-speed hand piece, pumice powder, and water, and stored in distilled water at $4{ }^{\circ} \mathrm{C}$. Eighty-eight enamel slabs $(4 \mathrm{~mm} \times 4 \mathrm{~mm} \times 2 \mathrm{~mm})$ were cut from the crowns of bovine incisors using an automatic cutting machine (Isomet, Buehler, Lake Bluff, IL, USA). The slabs were embedded in acrylic resin (Varidur, Buehler). The resulting blocks were flattened and polished, using the following sequence of abrasive papers: 600-, 1200-, 2400-, and 4000-grit (Buehler), under constant water cooling. At the end of the polishing procedure, the specimens underwent an ultrasonic bath with deionized water for $3 \mathrm{~min}$. Specimens without fractures or any other visual imperfections were then selected.

\section{Profilometric analysis}

After preparation, the specimens were submitted to profilometric analysis to select specimens with curvature $<0.3 \mu \mathrm{m}$. This analysis was performed with an optical profilometer (Proscan 2100, Scantron, Venture Way, Tauton, UK). The instrument sensor scanned an area that was $2 \mathrm{~mm}$ long (X-axis) and $1 \mathrm{~mm}$ wide (Y-axis), located at the center of the specimen. The equipment was set to go through 200 steps in the $\mathrm{X}$-axis, with each step measuring $0.01 \mathrm{~mm}$. In the Y-axis, there were 20 steps measuring $0.05 \mathrm{~mm}$ each. The curvature was calculated based on the subtraction of the mean height of the future test area from the mean height of the two reference surfaces using a specific software (Proscan Application software v. 2.0.17) [15]. Unplasticized polyvinyl chloride (UPVC) tapes were then placed on the selected specimens' polished surfaces, leaving a central window of $4 \mathrm{~mm} \times 1 \mathrm{~mm}$ exposed for subsequent testing.

\section{Initial lesion creation}

To create the initial lesion, specimens were immersed in $5 \mathrm{ml}$ of $1 \%$ citric acid (Sigma-Aldrich, St. Louis, MO, USA; $\mathrm{pH} 2.3$ ) solution, for $10 \mathrm{~min}$, at room temperature [15]. After, they were rinsed with deionized water and the tapes were removed. The specimens were submitted to a second profilometric analysis (using the same parameters described before), in order to check the depth of the lesions created. The mean SL for the specimens was $4.48 \mu \mathrm{m}(\mathrm{SD}=0.65)$. The specimens were then randomly divided into the 11 experimental groups $(n=8)$. Subsequently, the tapes were re-positioned on the polished surface of the specimens for the experimental procedures.

\section{Treatments}

The concentration of the active ingredients $\left(\mathrm{NaF}\right.$ and $\mathrm{SnCl}_{2}$ Sigma Aldrich, St. Louis, MO, USA) in the gels was chosen based on previous studies [15, 26, 27]. In the Sn-containing gels, $2.3 \mathrm{~g} / \mathrm{l}$ of D-gluconic sodium salt was added for stability purposes $[9,28]$. All the gels were manipulated with $0.5 \%$ of hydroxyethyl cellulose and had their $\mathrm{pH}$ adjusted to 4.5 , with either concentrated $\mathrm{HCl}$ or $1-\mathrm{M} \mathrm{KOH}$ solutions. Erythrosine and methylene blue were added in a concentration of $5 \%$. The placebo gel was manipulated with only hydroxyethyl cellulose, without any active ingredient/actives. Irradiation with the Nd:YAG laser (Power LaserTM ST6, Lares Research®, Chico, CA, USA) was performed on the test area, perpendicular to the specimen surface, with slow sweeping motion, in contact and focused, using a $400 \mu \mathrm{m}$ quartz fiber. The parameters used were the following: power of $0.5 \mathrm{~W}, 50 \mathrm{~mJ}$ of energy per pulse, $\sim 41.66 \mathrm{~J} / \mathrm{cm}^{2}$ of energy density, $10 \mathrm{~Hz}$ of repetition rate, and pulse duration of $120 \mu \mathrm{s}$. A trained operator performed the irradiation manually. It intended to cover the entire region of the formed lesion. The procedure was conducted in four 10$\mathrm{s}$ irradiations (two in vertical movements and the other two in horizontal direction). An interval of $10 \mathrm{~s}$ between the irradiations was necessary for thermal relaxation of the enamel tissue [15]. Before all irradiation procedures, power output measurements were taken with a power meter (Coherent, Newport, USA), to observe any power loss during irradiations, which did not occur.

The gels were applied in the exposed area of the specimens with a disposable applicator, for $120 \mathrm{~s}$. For the groups treated with the Nd:YAG laser, the irradiation was performed during the application of the fluoridated gels. The excess of the gel was removed with cotton rolls. After treatments, a third profilometric analysis was undertaken in order to verify whether the laser irradiation had caused any loss of dental tissues. The mean (SD) of SL obtained in this analysis was 4.38 (0.68), indicating that the treatments caused no further tissue loss. 


\section{Erosive challenges}

The specimens were then subjected to an erosionremineralization cycling model, which consisted of 5-min immersion in $0.3 \%$ citric acid solution (natural $\mathrm{pH}$ of 2.6), followed by 60 -min exposure to artificial saliva [29]. This procedure was repeated four times a day, for 5 days. All the experiment was conducted in ambient temperature $\left(\sim 25^{\circ} \mathrm{C}\right)$. Overnight, the specimens were stored in humid environment, at $4{ }^{\circ} \mathrm{C}$.

\section{SL determination}

At the end of the cycling process, the tapes were removed from the surface of the specimens and the fourth profilometric analysis was conducted, using the same parameters described above. An area $2 \mathrm{~mm}$ long $(\mathrm{X}) \times 1 \mathrm{~mm}$ wide $(\mathrm{Y})$ was scanned with the optical profilometer. The length covered both the treated area and reference surfaces. The step size was set at $0.01 \mathrm{~mm}$ and the number of steps at 200 in the $(\mathrm{X})$ axle; and at $0.05 \mathrm{~mm}$ and 20, respectively, in the (Y) axle. The depth of the treated area was calculated based on the subtraction of the average height of the test area from the average height of the two reference surfaces by using Proscan Application software v. 2.0.17. A 3-point height tool was applied [15]. The calculated depth was considered as the total surface loss.

\section{Statistical analysis}

SL data, obtained at the end of the experiment (fourth profilometric analysis), were analyzed for normal distribution and homoscedasticity with Shapiro-Wilk and Brown-Forsythe tests, respectively. Then, the comparison among groups was performed with one-way ANOVA and Tukey tests. The significance level was set at 5\%. SigmaPlot 13 software (Systat Software Inc., Chicago, IL, USA) was used for the calculations.

Fig. 1 Means (SD) of enamel surface loss for all groups. Different letters imply significant difference among groups $(p<0.05)$

\section{Results}

The means (SD) of the SL data are presented in Fig. 1. Group $\mathrm{F}+\mathrm{Sn}+$ laser presented the lowest SL, but they were not significantly different from $\mathrm{F}+\mathrm{Sn}(p=0.998), \mathrm{F}+\mathrm{MB}+$ laser $(p=0.974), \mathrm{F}+\mathrm{Sn}+\mathrm{MB}+$ laser $(p=0.75)$, and $\mathrm{F}+$ laser $(p=0715)$. These four latter groups did not differ among them and from $\mathrm{F}, \mathrm{F}+\mathrm{E}+$ laser, and $\mathrm{F}+\mathrm{Sn}+\mathrm{E}+$ laser $(p>0.05)$. The placebo showed the highest SL values, being not significantly different from placebo + laser $(p=0.526)$. The laser group was not different from placebo + laser $(p=0.599)$, but it presented significantly lower SL than the placebo gel group $(p=0.002)$.

\section{Discussion}

In this study, the addition of photo absorbers to fluoridated gels did not increase the combined effect of Nd:YAG laser and fluoride against enamel erosion, thus rejecting our hypothesis. $\mathrm{Nd}$ :YAG laser is an infrared laser with a wavelength of $1064 \mathrm{~nm}$ that is better absorbed by pigments. Previous studies suggest that pigmentation of the dental surfaces can result in increased Nd:YAG laser absorption [24, 30]. The use of photo absorbers would prevent a deep penetration of the laser irradiation in enamel and dentin, thereby enhancing its superficial effects and lowering the chances of pulp damage [24, 31]. The layer of dye over the surface would rapidly absorb the energy from the laser, thus increasing its temperature. The heat from the dye would be then transferred to the dental surface, where in combination with the energy that is directly absorbed by this tissue, will promote an effective melting [25].

Although most of the studies that tested the Nd:YAG laser irradiation with photo absorbers was concerning the occlusion of dentinal tubules, we assumed that the theory of an increased effect could also be true for enamel erosion prevention. However, according to the results of the present study, the laser could not enhance the protection given by the gels

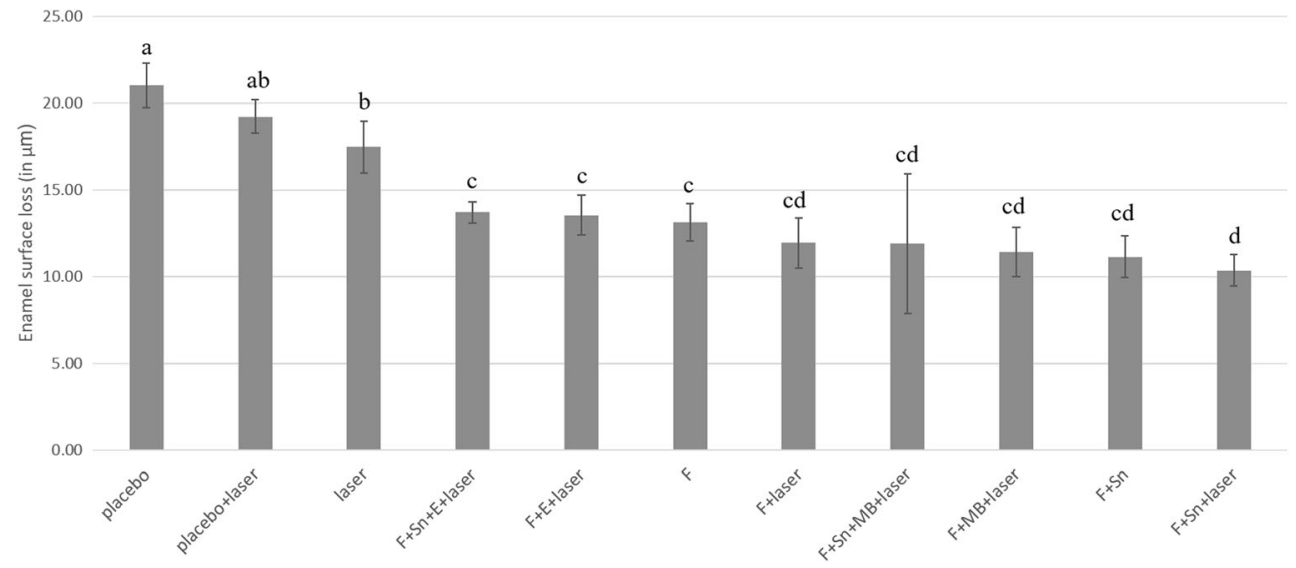


containing $\mathrm{F}$ and $\mathrm{F}+\mathrm{Sn}$, regardless of the presence of the photo absorber. Proposed mechanisms to explain the laseractivated fluoride effect would be related to an increase in fluoride deposition and uptake by the dental hard tissues [21], as well as the transformation of hydroxyapatite in fluorapatite [32]. Data showing the synergistic effect between fluoride and Nd:YAG laser against enamel erosion are, so far, inconclusive. After 5 days of erosive cycling, Rios et al. [17] were not able to observe such synergic effect. In their study, no photo absorber was employed, but the energy density was close to the one used in the present study (52.5 versus $41.7 \mathrm{~J} / \mathrm{cm}^{2}$, respectively). The authors observed that the combination of Nd:YAG laser with a NaF varnish $(2.26 \% \mathrm{~F})$ or an acidic phosphate fluoride gel $(1.23 \% \mathrm{~F})$ was no better than the varnish or gel alone. In other two investigations, triturated coal paste and higher energy densities were used for the laser irradiation, which was performed in association with topical fluoride application in different compositions and as different compounds $[33,34]$. In one of the studies, the laser only increased the anti-erosive effect of a titanium tetrafluoride $\left(\mathrm{TiF}_{4}\right)$ solution $(2.45 \% \mathrm{~F})$, but this was not observed for a $\mathrm{TiF}_{4}$ varnish $(2.45 \% \mathrm{~F})$ and for sodium fluoride varnish and solution (NaF, 2.26\% F in both) [33]. In the other, significantly lower mineral loss was observed by combining Nd:YAG laser irradiation and acidic phosphate fluoride gel $(1.23 \% \mathrm{~F})$ application [34]. From past reports, it is known that Nd:YAG laser irradiation with power settings lower than $0.6 \mathrm{~W}$ does not cause tissue damage in enamel $[35,36]$. To be within the safe range, in the present study, we have opted to use a power of $0.5 \mathrm{~W}$, resulting in an energy density of $\sim 41.66 \mathrm{~J} / \mathrm{cm}^{2}$ [15]. Based on these results, it is clear that the effect of the association between Nd:YAG laser and topical fluoride against erosion needs to be better determined. The use of higher parameters with photo absorbers, such as a triturated coal paste, seems to be an interesting option, but the temperature increase at the enamel surface and the possibility of ablation warrant further investigations.

The use of erythrosine and methylene blue as photo absorbers was chosen because both have shown a promising effect previously, where different conditions for sealing dentinal tubules with Nd:YAG laser were tested [25]. In addition, these dyes could be efficiently dissolved in the gels to achieve the desired concentration. It should be mentioned, however, that both dyes do not have maximum absorption bands that matches the Nd:YAG wavelength used, which may also help explain the lack of additional benefits observed. It also should be considered that the absorption of the laser irradiation by biological tissues depends on the presence of free molecules of water, proteins, and pigments [25]. In this sense, despite we have tried to standardize a very thin gel layer at the enamel surface, the possibility that the gel may have interfered with an effective interaction between the laser and the tooth should not be disregarded.
Despite not showing a positive synergy between the laser and fluoride, the Nd:YAG laser alone was able to significantly reduce enamel loss when compared to the placebo group. The mechanism in which lasers can prevent demineralization is not completely understood. However, it was hypothesized that due to its thermal effects, the laser can induce the formation of a less soluble enamel by decreasing its carbonate content and potentially forming pyrophosphates [37, 38]. In addition, the permeability of enamel is reduced, which was attributed to a sealing resulting of the melting and re-solidification, or to a partial degradation of the organic matrix, which leads to an obstruction of the inter- and intraprismatic spaces, thereby decreasing the acid diffusion pathways into enamel $[39,40]$. This result is contrary to a previous investigation conducted by our group [15], in which the Nd:YAG laser used alone, at the same parameters, fails to show any anti-erosive effect. The reason for these discrepant results may be related to the less aggressive erosive challenge herein performed, which used a lower concentrated citric acid solution $(0.3 \%$ versus $1 \%)$, in addition to a reduced frequency of acid challenges a day (four times versus six times). In view of this, it could be assumed that in the more aggressive erosive model, the surface modified by the laser was more rapidly removed, resulting in no prolonged protection [15].

Nevertheless, it must be pointed out that the protection offered by the laser was not comparable to the one promoted by the fluoridated gels. The effectiveness of fluoride in preventing enamel erosion was subject of many researches in the last years. Although there is evidence of an anti-erosive effect, it is thought to be limited, due to the more aggressive nature of the erosive challenges [41]. Sodium fluoride is a widely used fluoride compound, which can exert a protection against erosion by forming $\mathrm{CaF}_{2}$-like precipitates, especially when used at high concentrations and/or at low $\mathrm{pH}[41,42]$. Approaches to increase fluoride protection against erosion were suggested, with the use of fluoridated compounds containing metal cations, such as $\mathrm{SnF}_{2}$ and $\mathrm{TiF}_{4}$, which besides $\mathrm{CaF}_{2}$-like materials are able to form more acid-resistant surface precipitates [41]. However, in the present study, no significant difference was observed between the protection given by the F gel and a gel containing F and Sn. Similar finding was observed in João-Souza et al. [15]. In that study, the gel containing $\mathrm{F}+\mathrm{Sn}$ was in fact less effective than the gel containing F only. One of the hypotheses formulated to explain this result was that the carboxymethyl cellulose, an anionic molecule used as a thickening agent in the gel, might have reacted with $\mathrm{Sn}$, reducing its availability to interact with enamel. To overcome this issue, in the present study, hydroxyethyl cellulose was used to increase the viscosity of the gel, due to its neutral characteristics [43]. It could also be assumed that the mobility of Sn ions was reduced due to the high viscosity of the gel, rendering lower availability of $\mathrm{Sn}$ ions to interact with the enamel. Another possibility was related to the frequency of application, since most of the studies that showed a synergy between $\mathrm{F}$ and 
Sn were performed with solutions that were applied at least once a day $[9,28]$, whereas here, despite having higher concentrations of $\mathrm{F}$ and $\mathrm{Sn}$, the gel was applied only once, before cycling.

\section{Conclusions}

Under the conditions of this in vitro study, it can be concluded that all fluoridated gels and Nd:YAG laser irradiation were able to reduce enamel erosion, but the combination of treatments (fluoride plus laser) did not promote further protection. The addition of photo absorbers to the fluoridated gels did not influence the anti-erosive effect of the combination of laser plus fluoride.

Acknowledgments The authors would like to thank FAPESP (São Paulo Research Foundation, Grant Nos. 2012/20632-9, 2011/17699-1, and 2014/14055-4), CNPQ (National Council of Technological and Scientific Development, for the scholarship of the first author), and LELO (Special Laboratory of Lasers in Dentistry from the Department of Restorative Dentistry at the School of Dentistry of the University of São Paulo, Brazil).

\section{Compliance with ethical standards}

Conflict of interest The authors declare that they have no conflict of interest.

Ethical approval This article does not contain any studies with human participants or animals performed by any of the authors.

Informed consent For this type of study, formal consent is not required.

Funding The work was supported by the São Paulo Research Foundation (FAPESP, Grant No. 2014/14055-4) and the National Council of Technological and Scientific Development (CNPQ, for the scholarship of the first author).

\section{References}

1. Lussi A, Carvalho TS (2014) Erosive tooth wear: a multifactorial condition of growing concern and increasing knowledge. Monogr Oral Sci 25:1-15. doi:10.1159/000360380

2. ten Cate JM, Imfeld T (1996) Dental erosion, summary. Eur J Oral Sci 104:241-244

3. Addy M, Shellis RP (2014) Interaction between attrition, abrasion and erosion in tooth wear. Monogr Oral Sci 20:17-31. doi:10.1159/ 000093348

4. Lussi A, Schlueter N, Rakhmatullina E, Ganss C (2011) Dental erosion - an overview with emphasis on chemical and histopathological aspects. Caries Res 45:2-12. doi:10.1159/000325915

5. Schlueter N, Jaeggi T, Lussi A (2012) Is dental erosion really a problem? Adv Dent Res 24:68-71. doi:10.1177/ 0022034512449836

6. Jaeggi T, Lussi A (2014) Prevalence, incidence and distribution of erosion. Monogr Oral Sci 25:55-73. doi:10.1159/000360973
7. Scaramucci T, Borges AB, Lippert F et al (2013) Sodium fluoride effect on erosion-abrasion under hyposalivatory simulating conditions. Arch Oral Biol. doi:10.1016/j.archoralbio. 2013.06.004

8. Huysmans M-C, Young A, Ganss C (2014) The role of fluoride in erosion therapy. Monogr Oral Sci 25:230-243. doi:10.1159/ 000360555

9. Scaramucci T, Borges AB, Lippert F et al (2015) Anti-erosive properties of solutions containing fluoride and different film-forming agents. J Dent 43:458-465. doi:10.1016/j.jdent. 2015.01.007

10. Hove LH, Holme B, Young A, Tveit AB (2008) The protective effect of tif 4, $\mathrm{SnF} 2$ and $\mathrm{NaF}$ against erosion-like lesions in situ. Caries Res 42:68-72. doi:10.1159/000112816

11. Ganss C, Klimek J, Schäffer U, Spall T Effectiveness of two fluoridation measures on erosion progression in human enamel and dentine in vitro. Caries Res 35:325-330 doi: 47470

12. Venasakulchai A, Williams NA, Gracia LH, Rees GD (2010) A comparative evaluation of fluoridated and non-fluoridated mouthrinses using a 5-day cycling enamel erosion model. J Dent 38:S21-S29. doi:10.1016/S0300-5712(11)70005-7

13. Lagerweij MD, Buchalla W, Kohnke S et al (2006) Prevention of erosion and abrasion by a high fluoride concentration gel applied at high frequencies. Caries Res 40:148-153. doi:10.1159/000091062

14. Austin RS, Rodriguez JM, Dunne S et al (2010) The effect of increasing sodium fluoride concentrations on erosion and attrition of enamel and dentine in vitro. J Dent 38:782-787. doi:10.1016/j. jdent. 2010.06.009

15. João-Souza SH, Bezerra SJC, Borges AB et al (2015) Effect of sodium fluoride and stannous chloride associated with Nd:YAG laser irradiation on the progression of enamel erosion. Lasers Med Sci. doi:10.1007/s10103-015-1791-9

16. Magalhães AC, Rios D, Machado MADA et al (2008) Effect of Nd: YAG irradiation and fluoride application on dentine resistance to erosion in vitro. Photomed Laser Surg 26:559-563. doi:10.1089/ pho. 2007.2231

17. Rios D, Magalhães AC, de AM MMA et al (2009) In vitro evaluation of enamel erosion after Nd:YAG laser irradiation and fluoride application. Photomed Laser Surg 27:743-747. doi:10.1089/pho. 2008.2384

18. Tagomori S, Iwase T (1995) Ultrastructural change of enamel exposed to a normal pulsed Nd-YAG laser. Caries Res 29:513-520

19. Castellan CS, Luiz AC, Bezinelli LM et al (2007) In vitro evaluation of enamel demineralization after Er:YAG and Nd:YAG laser irradiation on primary teeth. Photomed Laser Surg 25:85-90. doi: 10.1089/pho. 2006.2043

20. Vlacic J, Meyers IA, Walsh LJ (2007) Laser-activated fluoride treatment of enamel as prevention against erosion. Aust Dent J 52:175180. doi:10.1111/j.1834-7819. 2007.tb 00485.x

21. Gao X-LX-L, Pan J-SJ-SJ-S, Hsu C-YC-Y (2006) Laser-fluoride effect on root demineralization. J Dent Res 85:919-923. doi:10. 1177/154405910608501009

22. Kwon YH, Kwon O-W, Kim H-I, Kim K-H (2003) Nd:YAG laser ablation and acid resistance of enamel. Dent Mater J 22:404-411

23. Zezell DM, Boari HGD, Ana PA et al (2009) Nd:YAG laser in caries prevention: a clinical trial. Lasers Surg Med 41:31-35. doi: 10.1002/lsm.20738

24. Yonaga K, Kimura Y, Matsumoto K (1999) Treatment of cervical dentin hypersensitivity by various methods using pulsed Nd:YAG laser. J Clin Laser Med Surg 17:205-210. doi:10.1089/clm. 1999. 17.205

25. Zapletalova Z, Perina JJ, Novotny R, Chmelickova H (2007) Suitable conditions for sealing of open dentinal tubules using a pulsed Nd:YAG laser. Photomed Laser Surg 25:495-499. doi:10. 1089/pho. 2007.2085

26. Pancote LP, Manarelli MM, Danelon M, Delbem ACB (2014) Effect of fluoride gels supplemented with sodium trimetaphosphate 
on enamel erosion and abrasion: in vitro study. Arch Oral Biol 59: 336-340. doi:10.1016/j.archoralbio. 2013.12.007

27. Ganss C, Klimek J, Schlueter N (2014) Erosion/abrasionpreventing potential of $\mathrm{NaF}$ and $\mathrm{F} / \mathrm{Sn} /$ chitosan toothpastes in dentine and impact of the organic matrix. Caries Res 48:163-169. doi: $10.1159 / 000354679$

28. Scaramucci T, João-Souza SH, Lippert F et al (2016) Influence of toothbrushing on the antierosive effect of film-forming agents. Caries Res 50:104-110. doi:10.1159/000443619

29. Scaramucci T, Borges AB, Lippert F et al (2013) Sodium fluoride effect on erosion-abrasion under hyposalivatory simulating conditions. Arch Oral Biol 58:1457-1463. doi:10.1016/j.archoralbio. 2013.06.004

30. Zhang C, Kimura Y, Matsumoto K et al (1998) Effects of pulsed Nd:YAG laser irradiation on root canal wall dentin with different laser initiators. J Endod 24:352-355. doi:10.1016/S0099-2399(98) 80133-7

31. Maleki-Pour MR, Birang R, Khoshayand M, Naghsh N (2015) Effect of Nd:YAG laser irradiation on the number of open dentinal tubules and their diameter with and without smear of graphite: an in vitro study. J lasers Med Sci 6:32-39

32. Meurman JH, Hemmerlé J, Voegel JC et al (1997) Transformation of hydroxyapatite to fluorapatite by irradiation with high-energy $\mathrm{CO}_{2}$ laser. Caries Res 31:397-400

33. Magalhães AC, Romanelli AC, Rios D et al (2011) Effect of a single application of TiF4 and NaF varnishes and solutions combined with Nd:YAG laser irradiation on enamel erosion in vitro. Photomed Laser Surg 29:537-544. doi:10.1089/pho. 2010.2886

34. Braga SRM, de Oliveira E, Sobral MAP (2015) Effect of neodymium: yttrium-aluminum-garnet laser and fluoride on the acid demineralization of enamel. J Investig Clin Dent. doi:10.1111/jicd.12185
35. Bedini R, Manzon L, Fratto G, Pecci R (2010) Microhardness and morphological changes induced by Nd:Yag laser on dental enamel: an in vitro study. Ann dell'Istituto Super di sanità 46:168-172. doi: 10.4415/ANN_10_02_10

36. Majori M, Manzon L, Pane S, Bedini R Effects of Nd:YAG laser on dental enamel. J Appl Biomater Biomech 3:128-133

37. Liu Y, Hsu C-YSC-YS, Teo CMJ, Teoh SH (2013) Potential mechanism for the laser-fluoride effect on enamel demineralization. J Dent Res 92:71-75. doi:10.1177/0022034512466412

38. Fowler BO, Kuroda S (1986) Changes in heated and in laserirradiated human tooth enamel and their probable effects on solubility. Calcif Tissue Int 38:197-208

39. Hsu C-YS, Jordan TH, Dederich DN, Wefel JS (2001) Lasermatrix-fluoride effects on enamel demineralization. J Dent Res 80:1797-1801. doi:10.1177/00220345010800090501

40. Nelson DGA, Wefel JS, Jongebloed WL, Featherstone JDB (1987) Morphology, histology and crystallography of human dental enamel treated with pulsed low-energy infrared laser radiation. Caries Res 21:411-426. doi:10.1159/000261047

41. Magalhães AC, Wiegand A, Rios D et al (2011) Fluoride in dental erosion. Fluoride Oral Environ 22:158-170. doi:10.1159/ 000325167

42. Ganss C, Schlueter N, Klimek J (2007) Retention of KOH-soluble fluoride on enamel and dentine under erosive conditions - a comparison of in vitro and in situ results. Arch Oral Biol 52:9-14. doi: 10.1016/j.archoralbio. 2006.07.004

43. Kadajji VG, Betageri GV (2011) Water soluble polymers for pharmaceutical applications. Polymers (Basel) 3:1972-2009. doi:10. 3390/polym 3041972 